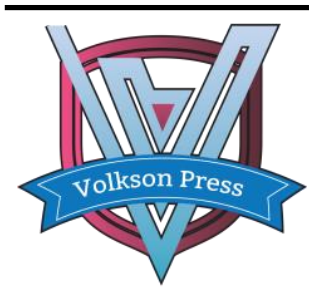

\title{
ANALYSIS ON FEATURES OF SOIL-RIVER-GROUND-PLANTS WATER BASED ON STABLE OXYGEN ISOTOPE IN POYANG LAKE WETLAND
}

\author{
Yuru Lin ${ }^{*}$, Zhimin Deng' ${ }^{2}$ Guohua Tang ${ }^{3}$ \\ ${ }^{1 *}$ Changjiang River Scientific Research Institute, Wuhan 430010, China; *lin_yuru@126.com \\ ${ }^{2}$ Changjiang Water Resources Protection Institute, Wuhan 430051, China; \\ ${ }^{3}$ Nanchang University, Nanchang 330029,China.
}

This is an open access article distributed under the Creative Commons Attribution License, which permits unrestricted use, distribution, and reproduction in any medium, provided the original work is properly cited

\section{ARTICLE DETAILS}

\section{ABSTRACT}

\section{Article History:}

Received 02 october 2017 Accepted 06 october 2017

Available online 11 october 2017

\section{Keywords:}

stable oxygen isotope, water supply, Poyang Lake wetland.
Poyang Lake is the largest freshwater lake in China, and the largest single area of habitat for migratory birds. The water level of Poyang Lake was declined continuous, and extreme droughts have frequently occurred in recent years, the structure and function of the wetland ecosystem were destroyed. In this paper, Stable oxygen isotopes was used as a tracer to identify composition of soil water, river water, ground water, and plants water. The focus was on characterize the variation with depth of the stable oxygen isotope composition and identifying the main sources of oxygen in soil water, ground water, river water and plants water, understanding the mechanisms of water movement among them. Soil water sampled at $10 \mathrm{~cm}$ intervals over the top $100 \mathrm{~cm}$ at two sections in the Poyang Lake wetland, and water samples collected from the plants, river water and ground water, were analysed for stable oxygen isotope composition, exploring the recharge and discharge of relationship between them. The results shown that the values of $\delta 180$ at depth of $0 \sim 30 \mathrm{~cm}$ at section I were declined with increasing soil depth, the value of $\delta 180$ at depth of $0 \sim 40 \mathrm{~cm}$ at section II had rare variation with increasing soil depth. The groundwater supply at section I was mainly influenced by precipitation, at section II was by precipitation and river water. The average value of $\delta 180$ in the domain species plants leaves of phalaris arundinacea, crex cinerascens, and phragmites communis was $0.9 \%,-4.23 \%,-5.25 \%$ respectively.

\section{INTRODUCTION}

Poyang Lake is the largest shallow freshwater lake in China, as well as an important international wetland. In recent years, high water level in Poyang Lake is gradually decreasing, while the time of low water level duration is increasing [1], and annual minimum water level has been on a decrease trend [2]. Extreme drought events have occurred frequently in Poyang Lake [3-6], changing of water level had significant influences on soil water content of bottomland. The low water level has represented more important reason for degradation of the wetland plants [7]. Therefore, study on the moisture source, migration and dynamic rules in circulation of soil-river-ground-plants by features of stable oxygen isotopes, had great significances on protection and recovery of wetland plants and sustainable development of wetlands ecosystem.

Analyzation of water stable isotope played an increasingly important role in studying moisture source, migration, dynamic rules and water resource utilization of plants in circulation of soil-river-ground-plants by analysed oxygen isotope ratio. Dawson and Ehleringer [8] shown that the water demand of plants growing along the river were rarely from the river water. By using the mix model of oxygen isotopes, Shen et al [9] applied the direct inference method and iso-source model to evaluate ponded water, soil water and ground water's contributions to rice crop by using stable isotopes of hydrogen and oxygen. Zhan et al used [10] the stable isotopes and hydrological data to analyse the interactions between precipitation, river water, lake water and shallow ground water in Poyang Lake. Zhang [11] analysed water supply sources of soil in Poyang Lake wetland by using stable hydrogen and oxygen isotopes. In this paper, we taken the Poyang Lake as study area, based on field acquisition of soil, river water, ground water and plants water, by useing stable isotope to analyse features of oxygen isotope and moisture sources in soil of wetland, and features of oxygen isotope with plants.

\section{Research area and data}

2.1 Research area
The Poyang Lake located in $115^{\circ} 49^{\prime} \sim 116^{\circ} 46^{\prime}$ E and $28^{\circ} 21^{\prime} \sim 29$ $52^{\prime} \mathrm{N}$, in administrative level it belong to Jiangxi Province, and downstream of Yangtze river. National Nature Reserve of Poyang Lake in Jiangxi have jurisdiction over 9 lakes, including Dahu Pool, Sha Lake, Beng Lake, Zhushi Lake, Meixi Lake, Zhonghu Pool, Dacha Lake, Xiang Lake and Changhu Pool, was an important international wetland with abundant biological diversity. The annual average temperature is $16.5 \sim 17.8^{\circ} \mathrm{C}$. The annual precipitation is $1,368.7 \sim 1,633.8 \mathrm{~mm}$, from April to June accounts for $46 \%$. The annual evaporation is $800 \sim 1,200 \mathrm{~mm}$, from July to September accounts for $50 \%$. Featured as the flood in summer and drought in autumn. Major flood period of Poyang Lake lasted from April to July, and the high water level were kept from August to September due to the flow jacking and backward with Yangtze River. The development soil type of wetland in Poyang Lake included red soil, paddy soil, yellowcinnamon soil, alluvial soil and moisture soil. The moisture soil were the typical wetland soil mainly distributed in the embankment and the ecotone of the lake basin. Wetland phytocoenosium in Poyang Lake distributed in annuluses along moisture gradient, due to lakeshore terrain slope, soil structure and water depth. Based on dominant community radio, carex cinerascens were the most widely distributed plants and covered the biggest area

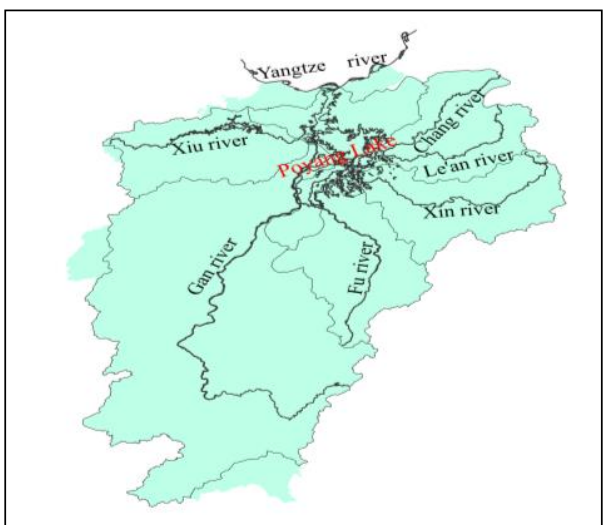


2.2 Data collecting and processing

Since the fluctuation of water level of Banghu affected a little by low water level period of Poyang Lake [12], two sections were arranged, section I was arranged at upstream of Xiu River along the Beng Lake, section II was arranged at downstream of Gan River along the Beng Lake, and each section was laid out four sampling points every 150m. In April 2014, 99 samples are taken from the river water, ground water, soil and plant, shown as Table 1, including 77 soil samples. Soil samples are taken by cylindrical auger boring with the depth of $100 \mathrm{~cm}$, sampling is taken every $10 \mathrm{~cm}$ deep, however, at the sampling point 4 (the deepest layer, about $90 \sim 100 \mathrm{~cm}$ deep underground) at Section II, soil sample cannot be taken due to soil texture and soil water content. Meanwhile, soil volumetric moisture content of each layer was measured by TDR instrument. 8 dominant species plants samples were gathered around soil sample points, dominant species at section I was phragmites, and at Section II was carex cinerascens. 8 ground water samples were gathered at soil sample points. 7 river water samples were gathered at the upper, middle and lower position of the sections, shown as Figure1.

All water samples were filled in $60 \mathrm{ml}$ with polyethylene plastic bottles, the bottle covers were sealed by seal membrane or plastic wrap to avoid bubble in the bottles and prevent evaporation of water sample, then the bottles were kept in incubator with ice bag before cold storage in the laboratory. Soil samples were placed in $8 \mathrm{ml}$ glass bottles, and the bottlenecks were sealed by plastic wrap before storage in the incubator. Plants samples were wrapped by freezer bags, and bag mouths were sealed by plastic wrap before storage in the incubator. Soil samples and plants samples were frozen in the refrigerator after back to the laboratory. Soil moisture and plants moisture were extracted by vacuum extraction device in Isotopic Laboratory of Chinese Academy of Forestry [13]. Stable oxygen isotope contained in water samples were measured in Stable Isotope Laboratory of State Key Laboratory of Water Resource and Hydropower Engineering Science in Wuhan University, $\delta 180$ content in water samples were measured by MAT253 isotope ratio mass spectrograph connected with Flash EA/HT, and the analytical precision of $\delta 180$ instrument was $0.3 \%$. Measure results of all water samples presented by micrometer on the basis of V-SMOW standard.

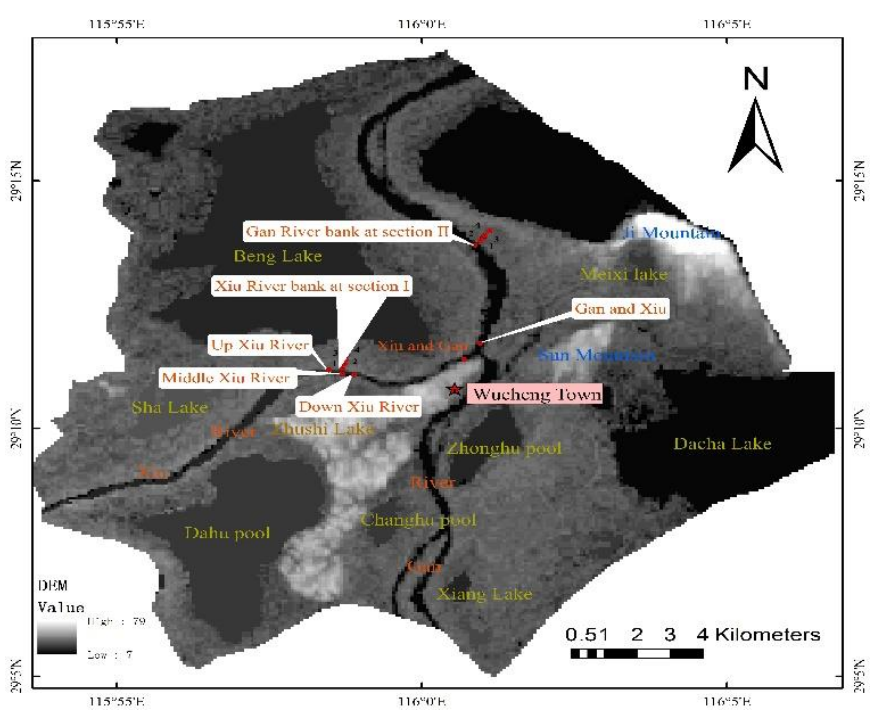

$$
\delta^{18} O=\left[\frac{\left({ }^{18} O /{ }^{16} O\right)_{\text {sample }}}{\left({ }^{18} O /{ }^{16} O\right)_{V-\text { SMOW }}}-1\right] \times 1000
$$

Tab.1 The types and number of samples

\begin{tabular}{ccccccc}
\hline sample & river & groun & \multicolumn{2}{c}{ soil water } & \multicolumn{2}{c}{ plants water } \\
\cline { 4 - 7 } types & wate & $\begin{array}{c}\mathrm{d} \\
\text { water }\end{array}$ & $\begin{array}{c}\text { sectio } \\
\mathrm{n} \text { I }\end{array}$ & $\begin{array}{c}\text { section } \\
\text { II }\end{array}$ & $\begin{array}{c}\text { sectio } \\
\mathrm{n} \text { I }\end{array}$ & $\begin{array}{c}\text { section } \\
\text { II }\end{array}$ \\
\hline $\begin{array}{c}\text { numbe } \\
\text { rs }\end{array}$ & 7 & 8 & 39 & 38 & 4 & 4 \\
\hline
\end{tabular}

The composition features of the oxygen isotope of soil water at section I shown as Figure 2(a). The values of oxygen isotope in the soil water were in a range of $-10.48 \%$ $-5.23 \%$, and the mean value was $-8.36 \%$. The values of oxygen isotope in soil water were decreased with increasing depth. The values of $\delta 180$ in soil water were concentrated at the surface of soil in the depth of $0 \sim 30 \mathrm{~cm}$, and were decreased with the increasing depth, due to the isotope fractionation caused by strongly evaporation of the moisture in surface soil. Oxygen isotope values of the deep soil below the depth in $70 \mathrm{~cm}$ had rarely variation. While the value of oxygen isotope were little at oil surface in the depth of $0 \sim 40 \mathrm{~cm}$ at sampling point 2 , and values were increased with the increasing depth, this trend was in keeping with results by Tian Richang [14], caused by the different plants covered. The composition features of the oxygen isotope of soil water at section II shown as Figure 2 (b).The values of oxygen isotope in the soil water were in a range of $-12.39 \% 0 \sim-6.55 \%$, and the mean value was $-8.63 \%$. The value of $\delta 180$ at the depth of $0 \sim 40 \mathrm{~cm}$ in surface soil water changed on the small side at each sampling point, standard deviation were $0.39,0.50,0.77$ and 0.24 respectively. Clark's [15] research shown that the composition of oxygen isotope almost had no change when the standard deviation of the $\delta 180$ value in the soil water was less than twice of analytical error. In this experiment, measurement accuracy of $\delta 180$ was $0.3 \%$, the composition of $\delta 180$ in the surface soil water were relatively stable, the reason might be that the dominant species of plants at sampling points in section II were carex cinerascens, which had large coverage $[16,17]$ and had small surface evaporation. Bristow and Horton's [18] research shown that mulch of soil had great influenced on physical environment of surface soil, especially at the depth of above $40 \mathrm{~cm}$ of soil. With the increased depth of soil, $\delta 180$ value changed in disorder. At the depth of $0 \sim 40 \mathrm{~cm}$, at sampling point 1 , the mean value of $\delta 180$ of soil water was $-9.71 \%$, at sampling points $2 \sim 4$, the values of $\delta 180$ were similar, the mean value was $-7.67 \%$. It's shown that soil permeability at sampling point 1 was better than other three sampling points, which may related to plants coverage. The oxygen isotope value at the depth of $60 \mathrm{~cm}$ of sampling point 1 and at depth of $80 \mathrm{~cm}$ of sampling point 3 were $-11.29 \%$ and $-12.39 \%$ respectively. The reason for small oxygen isotope value at the depth of $60 \mathrm{~cm}$ of sampling point 1 needs to be verified further, but effected from precipitation could be excluded. Figure 3 shown that the soil water content at the depth of $60 \mathrm{~cm}$ was lowest, it's impossible that precipitation flows to this area through the preferential flow form. At sampling point 3, the precipitation infiltrates into soil deeply through the preferential flow form due to soil pores.
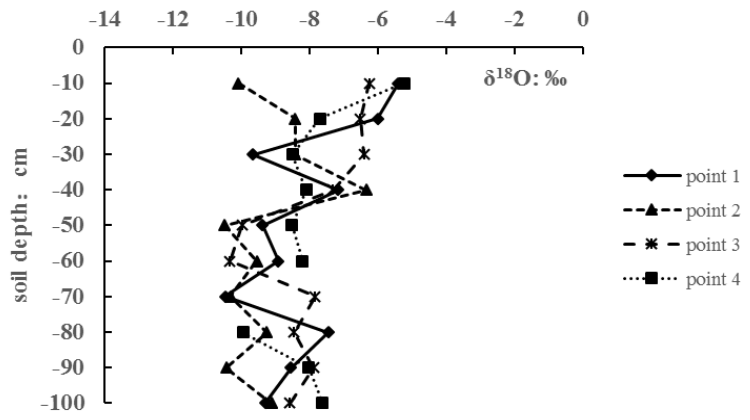

(a) section I

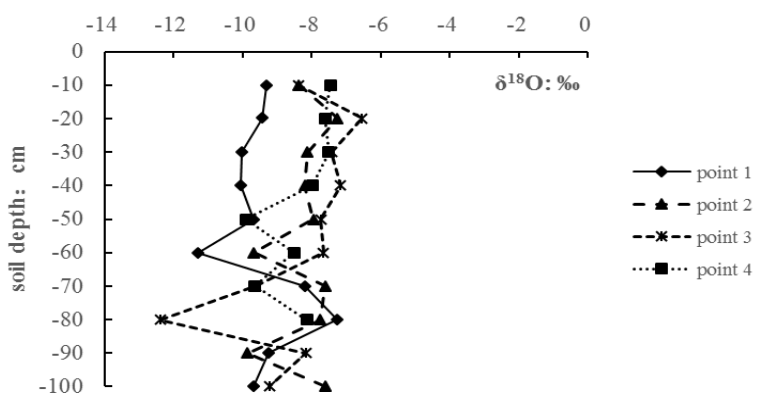

(b) section II

Fig. 2 ? $\delta^{18} 0$ value of soil water at different sections 


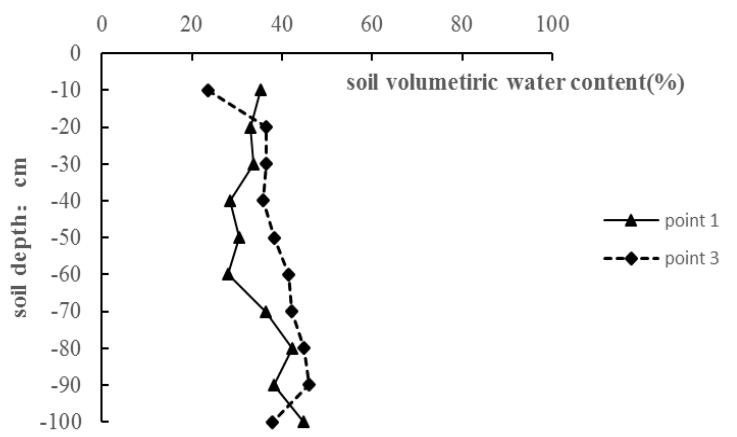

Fig. 3 The volumetric water content of soil at point 1 and point 3 in section II

\section{$3.2 \delta 180$ features of ground water and river water}

The composition features of the oxygen isotope of ground water at section I and II shown as Figure 4.The values of oxygen isotope in the ground water were respectively in a range of $-8.15 \%$ $~-6.64 \%$ and $-5.33 \%$ $3.14 \%$, and the mean value were $-7.13 \%$ and $-4.14 \%$ respectively. Oxygen isotope value of the ground water of section I was less than section II, four sampling points at each section, the oxygen isotope values of the ground water presented the same trends that at middle sampling points were greater than two sides, which might related to their respectively supply source and buried depth. Table 2 Shown that the buried depth of the ground water at section I was greater than that at section II, so the ground water at Section I influenced by evaporation was weaker and the isotope value was small than that at section II. Figure 5 shown that the oxygen isotope values in the Xiu River that flows through section I were in a range of $-7.24 \% \sim-3.43 \%$. Gan River flows through section II, at two sampling points in section II the oxygen isotope values were $-3.35 \%$ and $-4.64 \%$ respectively, expected "Up Xiu River" and "down Xiu River" these two points, the oxygen isotope value from river water were lower, others sampling points were basically similar. In general, the oxygen isotope value from river water in Gan River was greater than that in Xiu River, which is consistent with the results from Liang Yue[19]. Figure 4 and 5 shown that the oxygen isotope value of ground water from sampling points at section I were less than that from river water in Xiu River, while the oxygen isotope value of ground water from sampling points at section II were almost similar with that from river water in Gan River. According to the isotope value of local atmospheric precipitation [20], ground water at section I was mainly from precipitation, and at section II was from precipitation and the water of river and lake [11].

The depth of ground water shown as Table 2, combined with oxygen isotope values of soil water and ground water, we known that oxygen isotope value of the ground water at sampling point 1 of section I was similar to that in soil water of corresponding underground depth, while others sampling points' oxygen isotope values of the ground water were greater than that in soil water of corresponding underground depth, and all oxygen isotope values of ground water were greater than that in surface soil water (except that the values of oxygen isotope in ground water at sampling point 3 and 4 of section I were similar with that in the depth of $20 \mathrm{~cm}$ for surface soil water).These conclusions might be related to the borehole bored at field, plants types and its coverage, shallowed water lever of ground water and exposed heel without sealing, caused the strongly evaporation and $\delta 180$ enrichment.

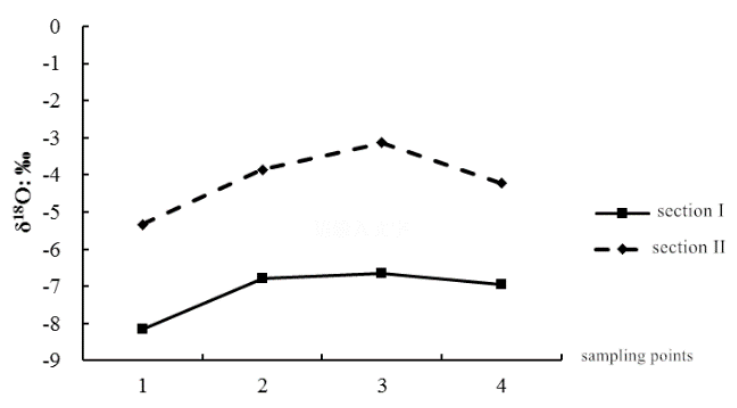

Fig. 4 团 $\delta^{18} 0$ value of ground water

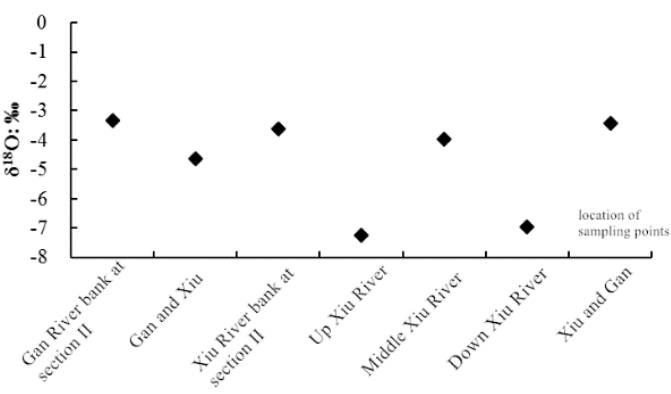

Fig.5 $\left[\delta^{18} \mathrm{O}\right.$ value of river water ${ }^{2}$

\begin{tabular}{cccccc}
\hline \multicolumn{2}{c}{ sampling points } & 1 & 2 & 3 & 4 \\
\hline $\begin{array}{c}\text { depth of } \\
\text { ground water }(\mathrm{m})\end{array}$ & section I & 0.65 & 0.7 & 0.97 & 0.85 \\
& section II & uncanned & 0.7 & 0.44 & 0.28 \\
\hline
\end{tabular}

\section{$3.3 \delta^{18} \mathrm{O}$ values of plants leaf water}

Oxygen isotope value in leaf water of surface dominant species plants at section I and section II shown as Figure 6. The research shown that the dominant species plants at section I and Section II were phalaris arundinacea, phragmites and carex cinerascens respectively, the oxygen isotope values in leaves water were in a range of $-6.52 \% \sim-0.9 \%$ and $5.04 \% \sim-3.58 \%$ respectively, the mean values were $-4.16 \%$ and $4.23 \%$ respectively. Oxygen isotope value in the leaves water of phalaris arundinacea was the largest, the mean value was $-0.9 \%$; and that of phragmites was the smallest, the mean value was $-5.25 \%$; and that of Carex cinerascens was located in middle, the mean value was $-4.23 \%$. There was a little difference in oxygen isotope values in plants leaf water of same dominant species plants, and at the same section with the different sampling points, the reason might be that the influence on plant transpiration varies from migration features of main element ( $\mathrm{Ca}, \mathrm{Mg}$, etc.) in different landform sections (sloping land, depression, etc.) [21].

Distribution and depth of plants root system were important factors to determine the moisture source used by plants [22]. Hair root of xeromorphic phragmites communis mostly distributed in the depth of $0 \sim 30 \mathrm{~cm}$ underground [23], root system of carex cinerascens generally distributed in the depth of $0 \sim 20 \mathrm{~cm}$ underground [24], and root system of phalaris arundinacea distributed in the depth of $0 \sim 30 \mathrm{~cm}$ underground. The oxygen isotope value of surface soil water corresponding to plants root system depth at different sampling points of two sections shown as Table 3. Only at sampling point 3 of section I the oxygen isotope value of soil water was similar with corresponding oxygen isotope value of plants leaf water, at others sampling points the oxygen isotope values of soil water were less than corresponding oxygen isotope values of plants leaf water, the reasons shown as: (1) the isotope fractionation was not occurred when water absorbed by plants root system and conveyed to leaves ${ }^{[25,26]}$, but when the leaf water directly contacted with the air, heavy isotope in leaf water will enriched with plant transpiration [27].(2) the distribution depth of plants root systems and the isotope value of absorbed water from soil were different, means the moisture source of plants were different.

Fig. 6 团 $\delta^{18} 0$ value of plants water

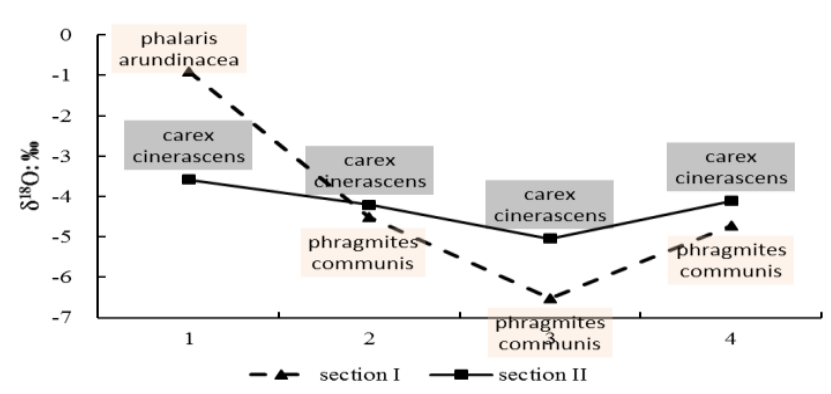

Tab. 3 The average $\delta^{18} \mathrm{O}$ value of surface soil at two sections 


\begin{tabular}{cccccc}
\hline & & & & & \\
section I & sampling points & 1 & 2 & 3 & 4 \\
\cline { 2 - 6 } & soil depth(cm) & $0 \sim 30$ & $0 \sim 30$ & $0 \sim 30$ & $0 \sim 30$ \\
& $\delta^{18} \mathrm{O}(\%)$ & -7.02 & -8.98 & -6.39 & -7.14 \\
\hline \multirow{3}{*}{ section II } & sampling points & 1 & 2 & 3 & 4 \\
\cline { 2 - 6 } & soil depth(cm) & $0 \sim 20$ & $0 \sim 20$ & $0 \sim 20$ & $0 \sim 20$ \\
& $\delta^{18} \mathrm{O}(\%)$ & -9.37 & -7.82 & -7.47 & -7.54 \\
\hline
\end{tabular}

\section{Conclusion}

Based on the field acquisition, the data included river water, ground water, soil water and plants water at two sections, by using stable isotopic technique, analysed the features of stable isotope in soil water, plants water, river water, and ground water, explored the moisture source relation between them, the following conclusions were drawn:

(1) The oxygen isotope in the soil water of section I was in a range of $10.48 \%$ o $-5.23 \%$, the mean value was $-8.36 \%$. Oxygen isotope in soil water at the depth of $0 \sim 30 \mathrm{~cm}$ of section I were enriched, and were decreased with the increasing depth. At sampling point 2, due to the plants coverage, the oxygen heavy isotope in soil water at the depth of $0 \sim 40 \mathrm{~cm}$ were increased with the increasing depth. The oxygen isotope in the soil water of section II was in a range of -12.39\% $6.55 \%$, the mean value was $-8.63 \%$, which was similar with the mean value of oxygen isotope in soil water of section $\mathrm{I} \delta^{18} \mathrm{O}$ composition in surface soil water at depth of $0 \sim 40 \mathrm{~cm}$ of section II were relatively stabled, due to the carex cinerascens large coverage of plant dominant species in the section and little influences on surface by evaporation.

(2) The oxygen isotope in ground water at section I and section II were in a range of $-8.15 \% 0 \sim-6.64 \% 0$ and $-5.33 \% 0 \sim-3.14 \% 0$ respectively, the mean value were $-7.13 \%$ and $-4.14 \%$ respectively. Based on oxygen stable isotope value in ground water, river water and lake water at two sections, and with buried depth of ground water, shown that the ground water in section I was mainly from precipitation, and in section II was mainly from precipitation, the river water and lake water.

(3) In the average value of oxygen isotope in the dominant species plants water of the Poyang Lake, phalaris arundinacea was the largest, the mean value was $-0.9 \%$; the second was carex cinerascens, the mean value was $-4.23 \%$; and phragmites communis was the smallest, the mean value was $-5.25 \%$.

\section{References}

[1] DENG Z M, ZHANG X, LUO W, et al. "Response of Poyang Lake wetland carex to the water level change", Journal of Basic Science and Engineering, 22(5), 865-876, (2014).

[2] OUYANG Q L, LIU W L. "Variation characteristic of water level in Poyang Lake over 50 years", Resources and Environment in the Yangtze Basin, 23(11), 1545-1550, (2014).

[3] LUO W, ZHANG X, DENG Z M, et al. "Variation of the total runoff into Poyang Lake and drought-flood abrupt alternation during the past 50 years", Journal of Basic Science and Engineering, 21(5), 845-856, (2013).

[4] Li X, Ye X. "Spatiotemporal characteristics of dry-wet abrupt transition based on precipitation in Poyang Lake basin, China", Water, 7(5), 19431958, (2015).

[5] You H, Xu L, Liu G, et al. "Effects of Inter-Annual Water Level Fluctuations on Vegetation Evolution in Typical Wetlands of Poyang Lake, China", Wetlands, 35(5), 931-943, (2015).

[6] Li M, Zhang Q, Li Y, et al. "Inter-annual variations of Poyang Lake area during dry seasons: characteristics and implications", Hydrology Research, nh2016308, (2016).

[7] HU Z P, GE G, LIU C L. "Cause analysis and early warning for wetland vegetation degradation in Poyang Lake", Resources and Environment in the Yangtze Basin, 24(03), 381-386, (2015). stream water", Nature, 350(6316), 335-337, (1991).

[9] Shen Y J, Zhang Z B, Gao L, et al. "Evaluating contribution of soil water to paddy rice by stable isotopes of hydrogen and oxygen", Paddy and Water Environment, 13(1), 125-133, (2015).

[10] Zhan L, Chen J, Zhang S, et al. "Isotopic signatures of precipitation, surface water, and groundwater interactions, Poyang Lake Basin, China", Environmental Earth Sciences, 75(19), 1307, (2016).

[11]ZHANG X, DENG Z M, PAN G Y, et al. "Variation in stable isotope composition in soil water in Poyang Lake wetland", Acta Ecologica Sinica, 35(22), 7580-7589, (2015).

[12] HU C H, JIANG J h, ZHU H H. "Analysis on water-level relationships between Banghu depression and Poyang Lake and its submersion and emersion of bottomland", Oceanologia et limnologia sinica, (6),617-623, (1997).

[13] West A G, Patrickson S J, Ehleringer J R. "Water extraction times for plant and soil materials used in stable isotope analysis", Rapid Communications in Mass Spectrometry, 20(8), 1317-1321,(2006).

[14] TIAN R C, CHENG H S, SONG X F, et al. "Characteristics of soil water movement using stable isotopes in red soil hilly region of northwest Hunan", Envirionmental Science, 30(9), 2747-2754, (2009).

[15] Clark I D, Fritz P. "Environmental isotopes in hydrogeology ", New York: CRC Press LLC, (1997).

[16] WU J D, LIUG H, JIN J F, et al. "Structure analysis of beach vegetation in Poyang Lake in autumn", Jiangxi Science, 28(4),549-554, (2010).

[17] HU D D, OUYANG K H, DAI Z H, et al. "Investigation on community characteristics and $\alpha$-diversity of Carex cinierascens meadow steppe in Poyang Lake wetland", Pratacultural Science, 30(6),844-848, (2013).

[18] Bristow K L, Horton R. "Modeling the impact of partial surface mulch on soil heat and water flow", Theoretical and applied climatology, 54(1-2), 85-98, (1996).

[19] Liao Y. "Biogeochemistry of heavy metal and nitrogen and isotopic tracing in Bang Lake(Poyang Lake)", Nanchang University, (2014).

[20] ZHAO H P, ZHANG X, DENG Z M, et al. "The characteristics of stable hydrogen and oxygen isotopes of atmospheric precipitation in Poyang Lake wetland", Journal of Water Resources Research, 4, 257- 264, (2015).

[21] LI W, LIU Y, YU L J, et al. "Characteristics of primary elements migration at different geomorphological positions and their correlation to plant transpiration in Guilin karst experimental section", Journal of Huazhong Agricultural University, 26(1), 55-58, (2007).

[22] DUAN D Y, OUYANG H. "Application of stable hydrogen and oxygen isotope in analyzing plant water use sources", Ecology and Environment, 16(2), 655-660, (2007).

[23] LI X C, HU S J, LI Y T, et al. "Study on the root distribution and soil water dynamics under Phragmites arid area", Acta pratacultural sinica, 17(2), 97-101, (2008).

[24] ZHU H H, ZHANG B, et al. "Poyang Lake-Hydrology Biology Deposit Wetland Development and rehabilitation". China Science and Technology University Press, (1997).

[25] Brunel J P, Walker G R, Walker C D, et al. "Using stable isotopes of water to trace plant water uptake"//Stewart G R. Stable Isotopes in Plant Nutrition, Soil Fertility and Environmental Studies. Vienna: International Atomic Energy Agency, 543-551, (1991).

[26] Alessio G A, De Lillis M, Brugnoli E, et al. "Water sources and wateruse efficiency in Mediterranean coastal dune vegetation", Plant Biology, (6),350-357, (2004).

[27] White J W C. Stable isotope ratios in plants. A review of current theory and some potential applications [A]. In: Rundel P W, Ehleringer J R, Nagy $\mathrm{K} \mathrm{A}$ et al. Stable isotopes in ecological research, ecological studies[C]. Springer, New York, 68: 142-162, 1989. 